\title{
Estágio supervisionado - papel da coordenação e do corpo docente na aplicação das Diretrizes Curriculares Nacionais ${ }^{\dagger}$
}

\author{
Mário Uriarte Neto*
}
* Coordenador do Curso de Odontologia da Universidade do Vale do Itajaí.

E m função do esforço e de alguns movimentos concretos no sentido de os cursos de Odontologia de Santa Catarina caminharem mais juntos, através da troca de experiências, uma delas inclusive na cidade de Joinville, em novembro de 2002, onde discutimos T.C.C. (trabalho de conclusão de curso) e estágio supervisionado e, também, porque queremos fortalecer nossa ABENO Regional, buscamos inicialmente um contato com os demais cinco cursos de semelhante natureza jurídica a fim de compormos nossa fala.

O estado de Santa Catarina possui sete cursos de Odontologia, no total: um federal e seis fundacionais de caráter privado. Excetuando o curso da Universidade Federal de Santa Catarina com aproximadamente quarenta anos de existência e o nosso, da Universidade do Vale do Itajaí, que está no seu décimo terceiro ano de implantação, todos os demais são muito jovens. Quatro deles: UNIPLAC, UNOESC, UNIVILLE e a UNISUL não formaram nenhuma turma. E a FURB formou sua primeira turma em 2002.

Para o curso de Odontologia da Universidade da Região de Joinville - UNIVILLE, já com uma matriz que contempla clínicas integradas de níveis de complexidades diferentes, todas as atividades de estágio são bastante recentes, tendo em vista que a primeira turma formou-se em agosto de 2003. Além das atividades desenvolvidas na instituição os(as) alunos(as) realizam, num sistema de rodízio, estágio em oito locais diferentes, propositadamente que buscam contemplar as futuras possibilidades de inserções no mercado. Segundo nos relatou o Coordenador, até o presente momento os relacionamentos com as parceiras - instituições governamentais e iniciativa privada -, têm sido bastante fáceis e proveitosos; e muito embora não tenham ainda uma avaliação mais apurada e concreta, as expectativas são grandes e promissoras.

A Universidade do Sul de Santa Catarina UNISUL, até o presente momento, para além das atividades clínicas integradas, o curso dispõe na matriz de um estágio supervisionado, sob a coordenação da disciplina de Odontologia em Saúde Coletiva, onde alunos(as) dos dois últimos períodos do curso realizam atividades de educação em saúde dentro da própria instituição. Conforme nos relatou um dos professores da equipe de coordenação, o grupo está em fase de discussão e estudo para a viabilização da implantação da nova matriz curricular, prevista para breve, pois formou em 09 de agosto de 2003, sua primeira turma.

Na Universidade Regional de Blumenau - FURB, as atividades clínico-integradas são desenvolvidas dentro da instituição. O curso formou sua primeira turma em 2002. Ocorrem atividades fora dos espaços físicos da instituição, de caráter educativo, por disciplinas isoladas, com o objetivo de dar ao(a) aluno(a) a possibilidade de aplicar o seu conhecimento em situações reais da vida em sociedade. Na visão do Prof. João Luiz Gurgel, a matriz não contempla totalmente o estágio supervisionado conforme propõem as Diretrizes Curriculares Nacionais. No entanto, o grupo também está em fase de estudos da mudança da matriz curricular, de planejamento e regulamentação do estágio interinstitucional e formalização de convênios com instituições envolvidas, previstos para os próximos semestres.

$\mathrm{Na}$ Universidade do Planalto Catarinense UNIPLAC, curso também com uma matriz que con-

†Participação na forma de painel "Estágio supervisionado - papel da coordenação e do corpo docente na aplicação das Diretrizes Curriculares Nacionais” na 38ª Reunião da Associação Brasileira de Ensino Odontológico. 
templa clínicas integradas de níveis de complexidades diferentes, o estágio envolvendo parcerias foi iniciado no $2^{\circ}$ semestre de 2003. E, nas palavras do Prof. Giovani de Mello, coordenador do curso, a idéia principal é a de formação humana, socialização do conhecimento em busca do ideal que é a Odontologia Preventiva. Continua: a expectativa é de oportunizar ao aluno estágio em vários locais e cidades, em orfanatos, colégios, empresas e unidades de saúde de secretarias municipais. Segundo ele, a maior dificuldade encontrada até agora foi com o poder público municipal de Lages, em função dos(as) profissionais receberem por produção, pois com o ingresso dos(as) alunos(as) ocorrerá a redução dos seus rendimentos. No entanto, existe um acordo com algumas prefeituras vizinhas, onde a situação é diferente. Na avaliação do professor até o presente momento os relacionamentos e os acordos têm sido razoáveis e as expectativas são grandes. A primeira turma concluirá o curso em julho de 2004.

No curso da Universidade do Oeste Catarinense UNOESC, o estágio supervisionado, principalmente no que se refere à modalidade interinstitucional, está dimensionado a responder as expectativas das novas Diretrizes Curriculares Nacionais, segundo a coordenadora Profa. Cláudia Wesoloski. As parcerias estão sendo buscadas com instituições do município e de cidades vizinhas, tanto com os poderes públicos quanto com a iniciativa privada. Até o momento as negociações têm sido satisfatórias e as expectativas são muitas, porém, as atividades só iniciarão no início de 2004. A primeira turma concluirá o curso em fevereiro de 2005.

O curso de Odontologia da Universidade do Vale do Itajaí - UNIVALI, desde a sua implantação, possui a disciplina de Clínica Integrada disposta nos dois últimos períodos, clínica de emergência e clínica de férias, esta última com duas edições realizadas. E atualmente atuação em Odontologia Hospitalar.

Para as primeiras turmas, no período de 1993 a 1995, dispunha de um estágio supervisionado desenvolvido em uma unidade de saúde da Secretaria $\mathrm{Mu}$ nicipal de Saúde. Esta parceria durou por aproximadamente três anos e, por questões administrativas foi interrompido.

A partir de 2001, em função de nossa participação nas reuniões da ABENO Nacional, e aqui vou abrir um parênteses para falar em nome dos demais cursos que citei anteriormente, que todos bebemos desta fonte e delas nos beneficiamos, também por indicação de comissões de avaliação e por valorizarmos inquietações e discussões freqüentes do grupo, iniciamos um processo de discussão com discentes e docentes acerca da importância e da necessidade além de outras adequações, projetarmos um estágio supervisionado interinstitucional na modalidade de supervisão indireta.

No primeiro semestre de 2002, deflagrou-se uma série de reuniões envolvendo as disciplinas de Clínica Integrada e de Odontologia em Saúde Coletiva (que ainda denominamos de Odontologia Social e Preventiva), Centro Acadêmico, líderes de turma e alunos(as) dos dois últimos semestres ( $8^{\circ}$ e $\left.9^{\circ}\right)$.

No final do primeiro semestre de 2002, a coordenação propôs, com a anuência do Centro de Ciências da Saúde (CCS), a formação de cinco câmaras para a composição do Colegiado de Curso, cada qual com a função de se dedicar mais especificamente a um determinado assunto e às quais todos os professores automaticamente deveriam estar vinculados. A proposta foi muito bem aceita pela maioria. Uma das câmaras passou a dedicar-se exclusivamente à matriz curricular, o que incrementou a sistematização da discussão também sobre o estágio supervisionado.

Simultaneamente, a coordenação e a disciplina de Clínica Integrada passaram a manter conversas com o poder público municipal, a fim de estabelecer a parceria e definir questões operacionais do estágio, que teria o formato de estágio supervisionado com supervisão indireta. Antes do início do estágio, promoveu-se uma reunião com os(as) profissionais das unidades que receberiam os(as) alunos(as). O grande desafio fora o de contemplá-lo dentro da matriz curricular vigente, pois tínhamos pressa e havíamos estabelecido o primeiro semestre de 2003 como marco inicial desta nova atividade.

Após todas as conversas e acertos, iniciamos o estágio e durante todo este semestre os trabalhos foram desenvolvidos. Experiência que relatamos em forma de pôster e estamos à disposição para maiores esclarecimentos.

Nossa experiência até aqui foi positiva. Encontramos dificuldade por conta da demora na tramitação burocrática do termo de convênio, por parte do poder público municipal. Em relação aos profissionais que receberam nossos(as) alunos(as), de um modo geral, o acolhimento foi muito bom. Tivemos um único problema com uma profissional que impediu o ingresso de alunos(as) para trabalharem na unidade de saúde, o que consideramos fato pontual e isolado.

O retorno que obtivemos dos(as) alunos(as), captado a partir de instrumentos previamente elabo- 
rados, foi bastante positivo e encorajador. Assim como também o foi por parte da própria Secretaria Municipal e dos profissionais.

Nossas expectativas são grandes. Estamos discutindo outras modalidades e mapeando novos locais para os próximos semestres, contemplando-os na nova matriz, cuja implantação está prevista para 2004, pois o processo encontra-se bastante adiantado.

Vemos, no estágio supervisionado, que entendemos, a partir da leitura das diretrizes, ter como principal característica o enfoque clínico integrado, ainda que com supervisão indireta como uma das modalidades, uma das possibilidades concretas de levar os alunos ao contato mais direto com o universo com o qual muitos se depararão logo após a formatura. Pois, conforme nos desafia o item V do art. $5^{\circ}$ das Diretrizes Curriculares Nacionais, devemos formar o profissional que possa exercer sua profissão de forma articulada ao contexto social, entendendo-a como uma forma de participação e contribuição social.

Acreditamos que o atendimento clínico integrado e, principalmente, em locais fora do ambiente da instituição, constituem-se num momento diferenciado e desafiador de aprendizado para o(a) aluno(a); pois na universidade, mesmo que atendendo a clientela oriunda do Sistema Único de Saúde, o ambiente relacional e emocional caracteriza-se pela presença de colegas de turma e de professores(as).

O mais importante, no nosso entendimento, é a oportunidade de podermos discutir as situações vividas e experienciadas pelo(a) aluno(a), fora da universidade, sem vaidade ou verdades absolutas e nem tampouco prepotência. Deparar-se com alguns quadros, analisá-los sem julgamentos prévios e encontrar, nos(as) professores(as), apoio para discuti-los e redimensioná-los deve constituir-se num comportamento rotineiro. Para isto, é preciso que se cultive uma relação de respeito e confiança entre professores(as) e alunos(as) e os parceiros.

$\mathrm{O}$ (a) aluno(a) precisa aprender a vislumbrar alternativas, por isso a importância deste tipo de estágio acontecer com alunos(as) de períodos mais avançados no processo de formação, a fim de efetuarem uma análise crítica do contexto e das relações encontradas no local de estágio. E, também, a entender que, como centro de formação, a universidade tem o compromisso de vanguarda; no entanto, é preciso que ele(a) também reconheça e presencie a realização de procedimentos que, mesmo sem todas as condições, respondem razoavelmente ao que está posto, comprometendo-o(a) com o processo de mudança e de melhoria das condições que, por vezes, o(a) incomodam tanto. Pois, temos como objetivo:

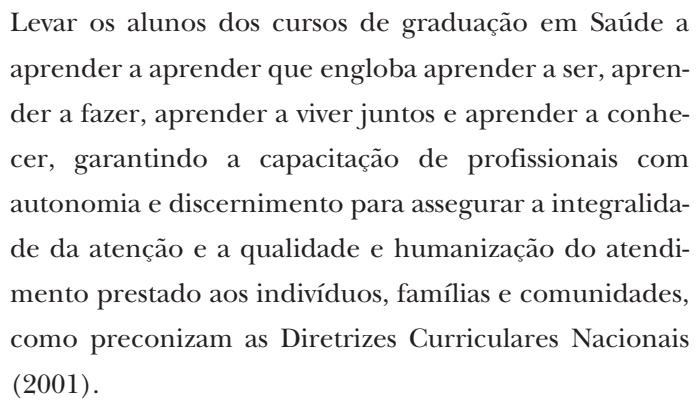

Devemos trabalhar esta questão sem hipocrisia, de maneira corajosa a fim de gerarmos benefício a todos neste processo. Principalmente à comunidade que, com a presença dos(as) estudantes, passa a contar com um maior investimento na questão da educação em Saúde, para além da realização dos procedimentos clínicos. Neste processo é importante salientar que devemos ter sempre presente a condição legal dos(as) alunos(as) que os impedem de trabalharem sozinhos no desenvolvimento das atividades clínicas, não devendo, portanto, em hipótese alguma, o(a) aluno(a) significar uma economia para empresas e/ou instituições, preterindo os(as) profissionais.

Até este momento centramos nossa fala sobre algumas considerações sobre o estágio supervisionado dos cursos de Odontologia de Santa Catarina. E agora teceremos breves considerações sobre o que consideramos papel da coordenação e do corpo docente na aplicação das Diretrizes Curriculares Nacionais.

Entendemos que em todo e qualquer processo de mudança cabe ao corpo docente o papel de analisar as referências, avaliar as experiências e discutir com os seus pares acerca da elaboração de possíveis propostas. No entanto, acreditamos que em áreas de atuação (formação) profissional como a nossa, onde muitos dos(as) professores(as) são oriundos dos consultórios, sem uma formação docente acadêmica pregressa, o movimento mais desafiador é o de nos percebermos de fato docentes: introjetarmos e assumirmos esta condição e termos claras todas as competências que nos são atribuídas formalmente.

Com certeza, esta percepção e reconhecimento do papel da docência, influenciam muitíssimo em toda atuação dentro da academia. Um cirurgião(ã)-dentista que se percebe como educador(a), sabe que é um instrumento auxiliar na construção 
do conhecimento, e que tem a responsabilidade de monitorar o preparo de seus(suas) alunos(as) para enfrentar, além das questões profissionais, sua própria vida dentro de preceitos éticos e humanos (FIGUEIREDO et al., 2001). Para isso, deve buscar não só nas referências institucionais, mas junto aos congêneres, parâmetros para organizar sua atuação, nas atividades de ensino, pesquisa e extensão.

$\mathrm{Ou}$, ainda, segundo BORBA (2001), o professor vive um clima de construção da sua profissionalidade. Como tal, pode resistir a uma pedagogia diferenciada, mas não pode desconhecer os avanços da ciência da educação e as múltiplas alternativas teórico-metodológicas disponíveis, que apontam para um ensino diferenciado.

Ressalto, neste momento, a exemplo do que provavelmente ocorre em muitos dos cursos, que as respostas, proposições e modificações observadas nos cursos, advêm principalmente do comprometimento e do entendimento, senão de todos, mas da maioria dos(as) professores(as) que se percebem verdadeiramente implicados(as) e atores(as) no processo de formação profissional.

Quanto ao papel da coordenação, no processo constante de mudanças, acreditamos competir-lhe o estar atento ao macro, às principais discussões e orientações apontadas freqüentemente por comissões, órgãos competentes e pelo mercado, por isso a importância da participação dos gestores em reuniões como esta. Também é sua função observar e ouvir o grupo donde, constantemente, emanam intenções, vontades, percepções, idéias e referências. No entanto, sua principal competência é a de atuar como mediador(a) entre as diferentes instâncias.

$\mathrm{E}$, finalizando, percebemos que, de um modo geral, todos os cursos, além de conscientes da constante necessidade de mudanças e adaptações, estão concretamente trabalhando para responderem às proposições das Diretrizes Curriculares Nacionais, a fim de garantirem o perfil profissiográfico desejado.

Acreditamos que, dentro de pouco tempo, estaremos socializando e discutindo nossas experiências que, com certeza, serão as mais diversas, tendo em vista as dimensões continentais do nosso país, que nos desvelam muitos "Brasis".

E agora mais do que nunca que a ABENO, para além de toda a contribuição verdadeira conferida aos cursos ao longo destes anos, coloca-se particularmente à disposição de todos, auxiliando-nos e encorajando-nos neste momento especial de mudanças de paradigmas e de atuação.

O desafio que está posto é muito grande, no entanto, não faltará o empenho e o esforço de todos, a fim de garantirmos uma melhor qualificação profissional, não só do ponto de vista técnico-científico, mas acima de tudo do ser humano que se reconhece no seu semelhante e do cidadão socialmente comprometido. Ou seja, nas palavras do cirurgião-dentista PATRICK HeSCOT a humanização da Odontologia precisa acompanhar o desenvolvimento técnico da profissão.

\section{REFERÊNCIAS BIBLIOGRÁFICAS}

BORBA, A. M. Identidade em construção: investigando professores na prática da avaliação escolar. São Paulo : EDUC, Itajaí : UNIVALI, 2001. p. 194.

CNE. Resolução CNE/CES 3/2002. Diário Oficial da União, Brasília, 4 de março de 2002. Seção 1, p. 10. Disponível em: http://www.mec.gov.br/cne/resolucao.shtm.

FIGUEIREDO, J. A. P. de et al. Apresentação de curso, simpósio, conferência e aula. In: ESTRELA, C. Metodologia científica: ensino e pesquisa em Odontologia. São Paulo : Artes Médicas, 2001. p. 457-469.

HESCOT, P. Futuro será a Odontologia humanizada. JABO, v. XX, n. 83, p. 14, maio/jun. 2003.

Aceito para publicação em 11/2003 